\title{
17. APTIAN CALCAREOUS SPHERULES INCERTAE SEDIS FROM DEEP SEA DRILLING PROJECT LEG 51, HOLE 417D, BERMUDA RISE
}

\author{
Hans M. Bolli, Department of Geology, Swiss Federal Institute of Technology, Zürich, \\ and University of Zürich, Switzerland
}

\section{INTRODUCTION}

Lower Cretaceous samples from Holes 417D and 418B in the Bermuda Rise were investigated for Calcisphaerulidae and spherules incertae sedis. It was thought that they may be present at these sites, as is the case in sediments of comparable age in several sites from the Indian Ocean (Leg 27) with Calcisphaerulidae present in only one site from the South Atlantic (Leg 40).

Apparently because of strong dissolution effects, no Calcisphaerulidae were seen in the investigated Bermuda Rise samples. However, Aptian Sample 417D-21-3, 109-111 cm was found to contain well-preserved, small spheres of 60 to $70 \mu \mathrm{m}$ in diameter, virtually identical to those described and figured from the Aptian and Albian of the Indian Ocean, DSDP Sites 260, 261, and 263 (Bolli, 1974). Similarly, the Bermuda Rise specimens consist predominantly of calcite and react very strongly to diluted $\mathrm{HCl}$. The washed residue which contained the spheres is very poor in $\mathrm{CaCO}_{3}$, as are those from the Indian Ocean. It contains only occasional, strongly corroded fragments of calcareous benthic foraminifers (nodosariids, lenticulinids). This and the presence of some fish debris points to strong $\mathrm{CaCO}_{3}$ dissolution of the sediment. However, there is an abundance of moderately preserved calcareous nannoplankton with its higher resistance, including the zonal marker Parhabdolithus angustus which is indicative of an Aptian age.

The possibility that the spheres might represent recrystallized radiolarians (or possibly artifacts) was discussed and discarded by the writer in his 1974 paper. Also, no new evidence for placing the spheres into a known taxon has come forward since their possible systematic association was discussed in 1974. It may be of significance that the Aptian Hole 417D specimens from the southern Bermuda Rise are recorded from sediments affected by strong $\mathrm{CaCO}_{3}$ dissolution, as are those of similar age from the Indian Ocean Sites 260 (middle Albian), 261 (Aptian), and 263 (upper Albian).

\section{MORPHOLOGY}

The surface features of the sphere, the size and the arrangement of the pores in a normally hexagonal pattern are virtually identical with those described and figured from the Indian Ocean Lower Cretaceous. Present on the test surface is also a restricted, faintly conical area without pores but with a minute nipple-like opening in its center (Plate 1, Figures 4, 5, 7, 8).

The interior walls of broken Indian Ocean specimens display pillar-like elements consisting of longitudinally arranged small rod-like crystals, which appear to reinforce the test wall (pl. 1, fig. 9, 12 in Bolli, 1974). Similar pillar-like elements are present also in a broken specimen from Hole 417D (Plate 1, Figures 1 and 2). Instead of rod-like crystals, these pillars are covered by delicate, very thin, leaf-shaped crystals, measuring $5 \mu \mathrm{m}$ in their largest diameter. It appears doubtful that they were part of the original wall structure; rather, they may be regarded as a secondary growth, possibly consisting of authigenic phyllosilicate. Whereas the Indian Ocean specimens from Sites 260, 261, and 263 occur in two distinct sizes (one of $\sim 50 \mu \mathrm{m}$, the other of about $80 \mu \mathrm{m}$ ), most of the examined Hole 417D specimens measure between 60 and $70 \mu \mathrm{m}$.

\section{OCCURRENCE}

The following samples of Hole 417D were investigated: $17-1,17-19 \mathrm{~cm} ; 17-2,5-7 \mathrm{~cm} ; 17-3,75-77 \mathrm{~cm} ; 19-1,80-82$ $\mathrm{cm}$; and $21-3,109-111 \mathrm{~cm}$. Of these, only the last listed contains the spheres incertae sedis described here. No Calcisphaerulidae were seen in the samples.

The following Hole 418B samples from the southern Bermuda Rise were investigated, ranging in age from late Aptian to Cenomanian: $27-1,34-36 \mathrm{~cm} ; 28-1,46-48 \mathrm{~cm}$; $28-1,130-132 \mathrm{~cm} ; 28-2,6-8 \mathrm{~cm} ; 29-1,38-41 \mathrm{~cm} ; 30-2$, $130-132 \mathrm{~cm} ; 31-2,84-86 \mathrm{~cm} ; 32, \mathrm{CC} ; 33-1,52-54 \mathrm{~cm}$; and $33-1,110-113 \mathrm{~cm}$. Most of them are void of calcareous remains and no Calcisphaerulidae or spheres incertae sedis were seen.

\section{REFERENCE}

Bolli, H. M., 1974. Calcareous organisms incertae sedis from the Lower Cretaceous of DSDP Leg 27. In Veevers, J. J., Heirtzler, J. R., et al., Initial Reports of the Deep Sea Drilling Project, v. 27, Washington (U.S. Government Printing Office), p. 909-913. 
PLATE 1

SEM micrographs of calcareous organisms incertae sedis. All figured specimens are from Sample 417D-21-3, 109-111 cm.

Figures 1, 2 1. Inside view of broken sphere, with pillar-like elements covered by delicate, very thin, leaf-shaped crystals. $\times 650$, C 34571 .

2. Close-up view of upper central part of Figure 1, showing leaf-shaped crystals covering pillars. Largest diameter of individual crystals is approximately $5 \mu \mathrm{m}$. $\times 2200$.

Figure 3 Sphere. Non-porous area is visible at top of specimen. $\times 500$, C 34572 .

Figure 4 Sphere showing the restricted (darker) non-porous area with a minute, nipple-like opening in its center. Pores of the sphere immediately surrounding this area tend to be smaller and more irregular in shape compared with those of the remaining surface. $\times 650, \mathrm{C}$ 34573.

Figure $5 \quad$ Close-up view of the non-porous area of Figure 4. The coccolith on lower right is a Watznaueria barnesae, the one on the upper left to the non-porous area a Parhabdolithus sp. $\times 1200$.

Figure 6 Sphere. View of part opposite to the non-porous area. $\times 650$, C 34575 .

Figure 7 Sphere showing non-porous area with minute, nipple-like opening. Pores immediately surrounding this area are smaller and more irregular in shape compared with those of the remaining surface. $\times 650, \mathrm{C}$ 34575 .

Figure $8 \quad$ Close-up view of non-porous area of Figure 7. $\times 1200$.

Figure 9 Close-up view of upper right part of Figure 7, displaying the low ridges which surround each pore in a hexagonal pattern. $\times 3000$. 
PLATE 1
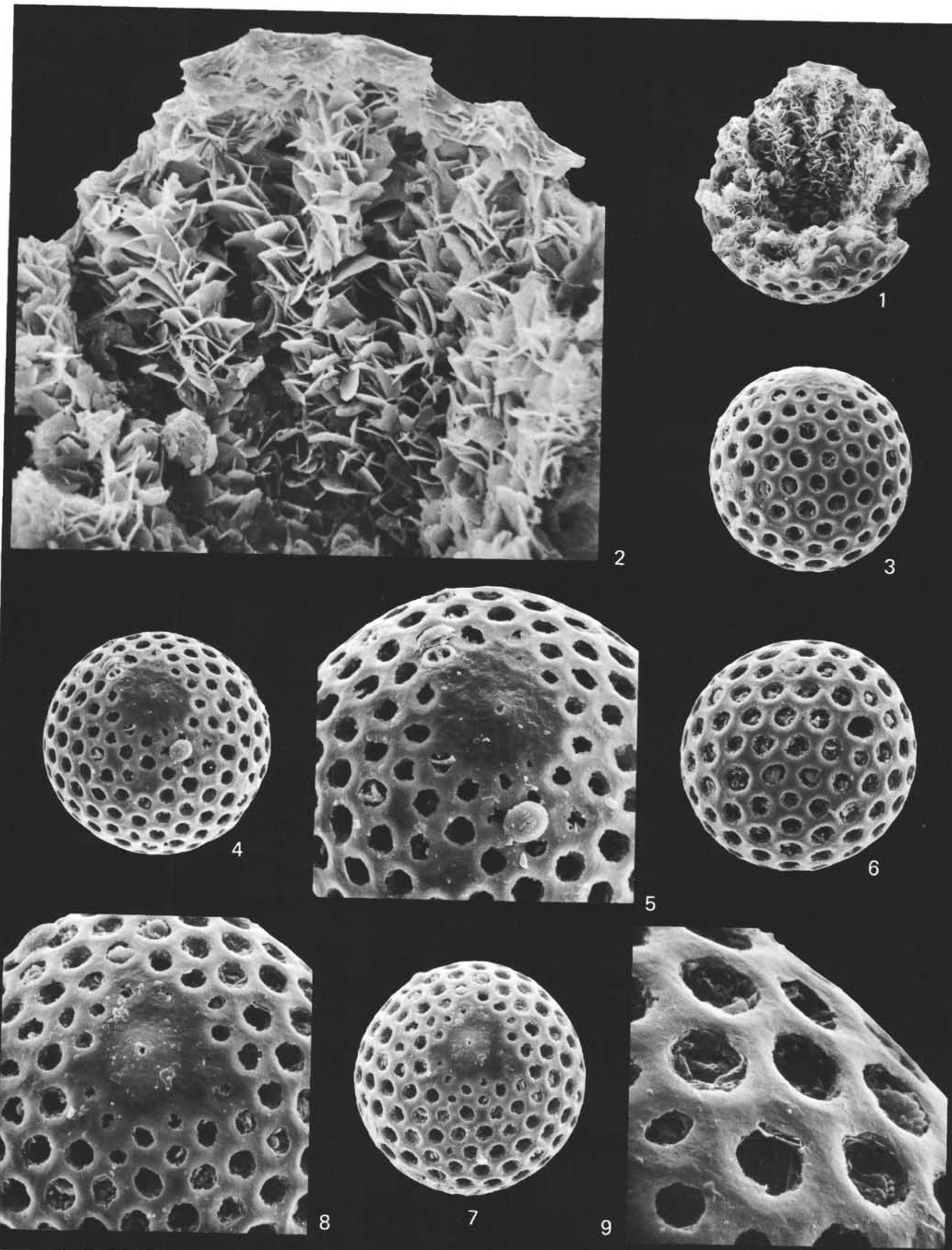